\title{
RECREATIONAL USE OF FOREST AREAS ${ }^{1}$ \\ By C. P. LYONS?
}

The many aspects of recreation with their various interpretations can be as confusing to correctly focus as the location of a tack on a dark bedroom rug. Unlike the tack which leaves no doubt as to its salient point, the subject of recreation has been twisted and turned, psychoanalysed, theorized, inflated and deflated.

For the purpose of this discussion, the innumerable deviations can be forgotten and only the simple fundamentals applied. No matter how obtuse the problem or complicated the conflict with other forest uses, the basic concepts of why man seeks recreation in the forests when correlated to well-established trends and hard lessons learned elsewhere should guide the solution.

The importance of forest recreation and its relationship to other forest uses can be outlined under four main headings.

1. What is Recreation and Forest Recreation in Particular?

2. What are the Special Requirements of Forest Recreation?

3. Correlation Through Multiple or Priority Use Forestry.

4. Co-ordination in Forest Administration.

Coming back to the first aspect which deals with the nature of recreation, let us imagine it is August and we are whisked to the roof of this building where a powerful telescope is mounted.

Peering here and there in this beautiful mountain setting where the green forests reach the very heart of the city, we might see these sights.

.... Three stenographers from Calgary, freed from the drudgery of office routine, awkwardly paddling a canoe on the Bow River.

.... A grocery clerk from Winnipeg who, after a year of being a most obedient servant, is now his own master. Crouched on the edge of a small lake, with camera on tripod, he expertly appraises the wind, sun and clouds so that the reflection of Mt. Rundle will etch sharply ion the water.

.... A business executive from Toronto sitting quietly and contentedly on the lawn of the Banff Springs Hotel, his ulcers at rest for the first time in many months.

Further observations would disclose an astounding number of people fishing, hiking, camping, riding or mountain climbing.

You might ask, "What's so unusual about all this? It's nothing more than recreation."

True enough. But let's take another imaginery glimpse through a telescope set up near the centre of Vancouver, Edmonton, Winnipeg, Toronto or any other large city of Canada. Now you are not looking into clean, healthful forest surroundings.

\footnotetext{
I Paper presented at the annual meeting of the Canadian Institute of Forestry. Banff, Aberta, October 11-13, 1951 .

- Assistant, Forester, Parks and Recreation Division, Department of Iands and Forests, Victoria. British Columbia.
} 
.... In a squalid, slum area a dirty, youngster thrills to the sound of smashing glass as he tosses rocks through a schoolhouse window.

.... A gang of teen-age toughs, hiding under a railroad trestle, plan a cowardly attack on a rival group and experience a sense of gratification through group organization and endeavour.

.... In a shoddy hotel room a dissolute character fixes a shot of dope and soon escapes from his everyday problems.

Do you now say "What's so unusual about all this? It's nothing more than recreation."

Perhaps you should, for a definition of recreation says: "It may be physical, intellectual, emotional or aesthetic; it may be active or passive; it may be engaged in virtually anywhere and at any time: it is individual, personal spontaneous and involves freedom of choice. It comprises all the endeavours in which man participates solely for the enjoyment they afford him."

The youngster throwing rocks, the man climbing a peak are both enjoying themselves - are engaged in recreation. Quite obviously, some activities are healthful, inspirational and educational while others are of negative value.

Recreation is not something that can be parcelled out here and there to deserving persons with no thought to the remainder. It is an essential part of living. After all, the vast majority of the population endures the daily grind, first to provide the basic essentials of food and shelter, then to achieve that which really makes life worthwhile-recreation! The important point to realize is that everyone, young or old, rich or poor, black or white, must have it, and it will be achieved in one way or another.

But why should recreation in the out-of-doors-the woods and mountains be stressed? Why not provide ample opportunities for movies, tennis courts, bowling alleys and spectator sports? Why necessarily use the forests where conflict with other aspects might arise? The answer can be found in a theory advanced by authorities on human behaviour, but one that is easily understood and substantiated in particular by foresters.

Man, like his ancestors before him, is essentially a running, leaping, throwing, fighting individual. His emotions are the same as those that governed the actions of his long-haired, long-armed forerunners. Hunting and fishing were part of his everyday living for tens of thousands of years, and the love of the chase, the pitting of skills against the elements of nature, remain rooted to some extent in most people today. Although the emphasis was on physical action, an appreciation of aesthetic qualities was definitely present for his early love for the wonders of nature are depicted through primitive carvings and rock drawings.

When man is in a forest contemplating some natural feature, fishing, hunting, camping or simply letting the peaceful quiet "re-create" his inner fount of energy, he feels instinctively that this is the natural, the right thing to do. It satisfies a natural, mysterious inner craving that finds expression in individual accomplishment whether it be in walking a log, building a campfre or shooting a grizzly bear. The emotional experiences of primordial life 
through eons of time are ingrained on man's very being and struggle for re-assertion.

The proven beneficial results in escaping from the dictates of custom and fashion to a natural environment are summed up thousands of times a year by medical doctors and psychiatrists to their troubled patients in the words: "Get away to the mountains or seaside for a change and rest."

With an ever-increasing tempo to modern living, getting away for "a break" is not just a pleasant fad-it is a must! The president of British Columbia's largest timber industry goes skiing every week-end during the winter, rain, blizzard or shine. Why? He says it is a necessity if he is to handle his job efficiently.

A prominent designing engineer outlines his approach to a new assignment as finding some quiet forest glade and there, with no attempt to even think of the matter, he relaxes watching the clouds overhead and casually noting the trifling actions of insects and birds. Sometimes he spends the whole afternoon with no more activity than filling his pipe. Then with body and mind "re-created" the salient points of the problem come easily to mind, largely without effort and free from distracting thoughts.

A leading investigator declares that public recreation is just as important a national concern as public health. Its impact only remains a matter of realization and education.

Now having outlined the important significance of forest recreation, let us examine the second point "What are the Special Requirements of Forest Recreation?"

Remembering modern man's attempt at gratification of associations ingrained in his basic nature, the most obvious requirements is a natural outdoor area for these pursuits. It is almost axiomatic that such regions in Canada are forests of one type or another and may range in size from thousands of acres of virgin forest to a half-acre glade of shady aspen.

Since, primarily, we must deal with the diversified needs of individuals, it follows that a great variety of outdoor opportunities should be provided. It is significant to note that many years ago the United States Forest Service classified 22 separate types of outdoor recreational areas with special features and administrative policy for each.

A number of these might well be examined closely in Canada today for they signify well-established trends and wants which could be instituted now with little or no conflict with other forest use.

One such reserve is a wilderness area which is not less than 100,000 acres retained in a wild or natural state. For the last decade many persons and organizations in the United States have realized that such reservations are entirely inadequate in view of a rapidly increasing population and a growing trend toward forest recreation. The problems encountered in establishing new wilderness are difficult and immensely costly.

But what of Canada with no designated wilderness areas at this late date? The subject is usually dismissed with a few waves of the hand and the trite remark that much of Canada is still a wilderness-exactly the same 
narrow reasoning which, for many decades, accompanied the wholesale depletion of this nation's timber reserves. Wilderness areas to serve the purpose intended must be where they can be used and not relegated to far Northern wilds or impregnable mountains. Would it not be well to profit now by the lessons learned elsewhere in so costly a fashion? Should not such areas be established immediately with sufficient regulations and defined policy to keep them inviolate?

The U.S. Forest Service lists other reserves such as primitive and natural areas, roadside and waterfront zones, winter sports areas, resort and organization sites, historical and geological areas and camp and picnic grounds. Such a pattern allows for a variety of tastes and does, in almost every case, constitute a direct link with the forest and forest administration.

The wide scope of these reservations, embracing areas from a few to hundreds of thousands of acres, likely appear as a serious threat to other forest use. The question now arises as to how much forest land is required for recreation and how it will fit in with the general forestry program. This phase, forming the third portion of the discussion, has been headed: "Correlation of Requirements by Multiple or Priority Use Forestry."

When considering the largely theoretical question of how much forest land is needed, it is not sufficient to take into account only present populations, tourist trade or access. Past trends toward higher populations, popularity of outdoor recreation, shorter work hours, cheaper and faster transportation and higher standards of living have, in less than 30 years, resulted in an 8-fold increase in number of visitors to the National Forests. These factors apparently will never be static and their defined trend can be projected into the future with fair safety. Failure to recognize this significance in time is seen in the Eastern states and provinces by the dire lack of convenient recreational areas. Even in British Columbia, the symbol of primitive forest, the problem of over-use is acute on all areas within easy reach of cities.

John Sieker of the Division of Recreation and Lands, U.S. Forest Service, in a recent paper "The Future of Forest Recreation" makes these stadied statements of conditions 50 years from now. "There is a universal awareness that forest land suitable for recreation is barely enough to accommodate the use-if the land is given the best management and protection", and further, "Everyone wonders why it took everyone so long to realize what everyone now knows about the importance of forest recreation and the wise management of forest lands."

How quickly the picture of recreational wants can change has been vividly demonstrated in British Columbia where, within a period of several years, an area of very meagre settlement and recreational requirements will develop into a heavily populated industrial region. New highways likewise will bring urbanization to areas that have only been strange sounding names on maps. What will their recreational requisites be 20 years from now? By then will all the nearby lakes and streams be logged to the water's edge: spawning streams choked or scoured so as to be worthless; the most suitable park areas privately owned and the scenic attractiveness of highways and riverways de- 
stroyed through too intense commercialism of the natural resources? Recreational planners must look well into the future and be acutely aware of the value of the many things now loosely evaluated as intangibles and remaining as such to most people until they must be restored or purchased for cold cash.

Aside from the requirements of residents, consider the potential value of our tourist industry. For example, British Columbia's tourist industry is rated at $\$ 35,000,000$ annually. It sounds impressive to the residents but compare it to the State of Michigan, where a State one-seventh the size, logged and almost completely denuded early in the century, makes the most of its recreational potentials and now has a 600-million-dollar tourist industry.

Primarily, tourists come to Canada because they consider it a last forest retreat. Forests mean cool lakes, fishing streams, scenic drives and relaxation. Here is a forest resource that can be cropped every year, not once in eightya lucrative associated industry during the long tree-growing period!

In our forest administration let us keep an eye to these present and future possibilities, and seeing what has been done in countries with far less to offer, give some thought to the welfare of the forest goose that, with care, can produce golden eggs as well as feathers.

The question of how much forest is needed for recreation in view of present and likely demands can be divided into those conventional and recognizable parks and reserves of unquestionable merit and the problematical remainder that could result through multiple or priority use forestry.

In considering the first, the principle of setting aside outstanding scenic areas as national or provincial parks is generally conceded as sound policy. So, too, should be provision for scenic highways through forest areas with a bordering strip of trees rather than the tangle of dangerous slash that is so often seen. And why, out of the millions of acres in each province, should there not be one accessible piece of each representative virgin forest type for study and record. Some other recognized uses cover organized group activities, highway camp and picnic sites and the preservation of outstanding geological and historical features. In general, it is not too hard to perceive the value of such reserves. Their number and extent will depend largely on population density and the richness of a province in suitable natural features.

It is in attempting to correlate forest recreation in a commercialized forestry program that planners often run into conflicts with other phases of forest management. In trying to find a basis for reconciliating difference, the principle of multiple use forestry invariably arises. Its ideal adoption is perhaps best outlined as the central guiding policy of the U.S. Forest Service in that of providing for "the greatest good to the greatest number in the long run."

Can this be taken as an absolute guiding principle? "A Study of the Park and Recreation Problem of the United States" maintains: "Multiple use is an Utopian theory. In the first place it does not recognize the nature of the recreational resource which consists of the other resources in combination 
. . f failing to recognize the dominant use of a given area, detracts from its value by giving equal opportunities for the exploitation of subordinate resources. This is apt to be little more than multiple abuse ...."

Supporting this criticism is a somewhat different approach to forest use as outlined by Everett Jensen, a forester in California. He suggests that perhaps the simplest method is the dedication of certain areas to their most obvious uses but hastens to point out that the "obvious" is not necessarily the final or "highest" use. He stresses that public need and opinion must be the final judge and planning should be based on that premise. From an analysis of long-term forest use trends in Southern California, the following order or priorities has been established in event of serious conflict:

1. Water

2. Recreation

3. Timber

4. Wildlife

5. Domestic Stock Forage or Grazing

This priority scale sets out two concepts that generally are disregarded in Canada. The first is that, in the long run, a great number of forest areas can become more important for recreation than timber production and second, that wildlife values can rank ahead of domestic grazing.

Obviously, every forest cannot be classified immediately with the above priority scale to govern its management and, in application, Jensen says there is presupposed a progression to higher use with a modification or elimination of the lower use. Such a scale permits recognition of changing pressures on the forests.

There remain two important factors in this common sense approach to forest planning. The first is that the priority progression scale be fully recognized and that decisions made effecting a minor or low priority use which may be dominant at present should neither complicate nor destroy the potential of higher uses when a changeover is made.

The second point is the recognition of a definite planning period. This is defined as "The number of years ahead during which trends in public demand can reasonably be forecast for the land unit in question." Any contracts or plans are so formulated as to terminate or be capable of changeover at the end of this period. Such a straightforward approach to forest use would appear ideal from recreational standpoints and requirements.

In concluding with the fourth heading of this paper, namely, Co-ordination in Forest Administration, an illustration is cited which, it is hoped, is typical enough to show both the recreational planner's attitude and to provide a stimulant for sympathetic assessment of forest potential by all foresters.

A small provincial forest set aside over 20 years ago in a relative wilderness region for its timber production potential is now within reasonable access due to highway construction. Furthermore, it lies adjacent to an area that has become almost world famous for its hunting and fishing - one already taxed to the utmost to cater to the large influx of visitors. Nowhere in the 
Province is there such a concentration of lakes as in this forest, over 300 in fact, each still in its natural setting and most naturally stocked with fish.

Because the basic object of timber production has never been challenged, no recreational surveys made, and the extremely fine recreational possibilities hidden from the public eye, it appears almost certain that logging will proceed in single-minded fashion to the appreciable detriment of water and recreation resources.

Would it not be better to take the long-term viewpoint and, using a plan like Mr. Jensen's, adjust the logging pattern to protect the more important watersheds and leave major recreational values unimpaired? Cutting operations could be planned for a definite period and then a revised plan made on the basis of changed public needs and opinions.

If logging were planned carefully, sufficient cover would be left for wildlife and probably the hunting potential improved. Lakeshores would remain attractively clothed in trees, with suitable surroundings for resorts, fishing and hunting camps, camp and picnic sites and, possibly, a very large number of summer homes. Logging roads with fringes of protective timber could be adapted to recreation access routes. Then while the forest was growing the next crop, many recreational activities could take place without any detriment to the final product. The publicity value and public goodwill from such a type of planning would be an immense asset to the forestry programme. Financial returns would be considerable also. Bear in mind that an average acre of this forest would only return about $\$ 3$ a year based on an annual increment of 300 f.b.m. whereas 3 summer homes on the same acre would bring in fifteen or twenty times that much.

In conclusion, forest recreation should not be regarded as a troublesome and unnecessary fifth wheel in the forest program. Those engaged in planning this resource have frequent occasion to see examples of a type of forest management that has thoughtlessly and unnecessarily destroyed wildlife, watershed and recreational values. We look to the growing conservation movement in Canada, the increasing public realization of our overall forest potential and, most of all, the acceptance by foresters that a tree may be of more value to sit under, tie a tent to, shelter a deer or protect a watershed than enjoy a brief moment of glory classified on the scaler's sheet as 350 f.b.m. 